\title{
Cultivating Iranian IELTS Candidates' Writing Skills through Online Peer Feedback: A Mixed-Methods Inquiry
}

\author{
Afsheen Rezai (D) \\ Department of Teaching English and Linguistics, Ayatollah Burojerdi University, Borujerd, Iran \\ Correspondence should be addressed to Afsheen Rezai; afsheen.rezai@abru.ac.ir
}

Received 25 December 2021; Accepted 18 January 2022; Published 21 February 2022

Academic Editor: Ayoub Bahnasse

Copyright (c) 2022 Afsheen Rezai. This is an open access article distributed under the Creative Commons Attribution License, which permits unrestricted use, distribution, and reproduction in any medium, provided the original work is properly cited.

\begin{abstract}
Though peer feedback has gained noticeable attention in second-language (L2) education in face-to-face classes, its effects on improving IELTS candidates' writing performance have remained unexplored in the Iranian EFL context. Thus, the present study aims to reach a two-fold purpose. First, it investigates the effects of online peer feedback (OPF) on improving Iranian IELTS candidates' writing performance. Second, it explores what the IELTS candidates' perceptions are about the efficacy of online peer feedback to cultivate their writing performance in the Iranian EFL context. To these aims, having been homogenized through the Oxford Quick Placement Test (OQPT), a total of 35 IELTS candidates were randomly assigned into an experimental group and a control group. The two groups went through pretest, treatment, posttest, and delayed posttest procedures. To collect the required qualitative data, 5 participants of the experimental group participated in a focus group interview. The data were analyzed using a one-way ANCOVA and content analysis. Findings documented that the experimental group outperformed the control group on the posttest and delayed posttest. Additionally, the qualitative results revealed that the participants had positive attitudes toward the potentials of OPF to cultivate writing skills. The study ends with proposing a range of implications and suggestions for further research.
\end{abstract}

\section{Introduction}

Over the last decades, writing skill has gained noticeable attention. A major reason for this ongoing attention lies in the fact that globalization has pushed individuals with different cultural and linguistic backgrounds to be involved in constant long-distance communication [1]. In actual fact, with the quick development of the modern social media technologies, individuals' needs to exchange their meaning have accelerated and extended. As Hyland [2] noted, this phenomenon has led to revising the writing notion to include communicative purposes and social interactions. Browker [3] considered writing as a crucial communicative skill to meet life's needs. Thus, writing can be considered as a system for interpersonal communication, playing a key role in personal and professional lives.

Writing as a productive skill has been found a very demanding skill for the second-language (L2) learners [4-6]. According to Brown [7], this problem is due to the fact that
L2 learners need to "attend to a number of principles for designing and developing the appropriate writing product" (p. 442). This issue is also true for Iranian IELTS candidates. As Azabdaftari and Mozaheb [8] stressed, the Iranian IELTS candidates usually do not perform well on the writing part of the IELTS exam. IELTS instructors and candidates often complain about the quality of the writings, and they blame that the cultivation of the writing competence occurs very slowly [9]. This long-lasting problem has persuaded IELTS instructors and candidates to seek for new approaches and techniques $[10,11]$. One of the techniques which has been presented to alleviate this problem is peer feedback $[12,13]$. Peer feedback is useful from two perspectives: informational value, supporting learning and motivational value, and stimulating efforts [14].

Considering the importance of writing skills for IELTS candidates and the quick development of social networking apps, it is worth exploring if online peer feedback (OPF) can lead to improving the Iranian IELTS candidates' writing 
skills. In a sense, it is required to examine if OPF can set a setting wherein IELTS candidates consolidate their writing competencies. Despite this urgent need, the literature reveals that the effects of OPF on the improvement of Iranian IELTS candidates' writing skills have remained unexplored. To fill up this lacuna, the present study aims to investigate the effects of OPF on improving IELTS candidates' writing skills, as well as to explore their perceptions of the efficacy of OPF to cultivate their writing performance. It is hoped that this study's findings can be of great help for IELTS instructors and candidates to find a new way to ameliorate substantially the common writing problems.

\subsection{Literature Review}

1.1.1. Online Peer Feedback. Peer feedback has been referred under different terms, such as peer review, peer editing, peer response, and peer evaluation. According to Liu and Hansen [15], peer feedback is using learners as sources of input and information to others. In peer feedback, they added that "learners assume roles and responsibilities normally taken on by a formally trained teacher, tutor, or editor in commenting on and critiquing each other's drafts in both written and oral formats in the process of writing" (p. 1). The theoretical underpinning of peer feedback rests upon the sociocultural theory of Vygotsky [16]. He claimed that knowledge is constructed through the interaction between an individual and the environment. Instead of considering learning as an individual activity, it is perceived as a cognitive activity which is coshaped through the interactions among individuals and the surrounding. Hence, peer interaction and peer feedback are of paramount importance since they let learners co-construct knowledge [17, 18].

There are some notable advantages to peer feedback. It encourages learners to be more active in the classroom [19], increases learners' engagement and time spent on tasks [20], decreases writing apprehension and increases writing confidence, develops learners' critical thinking, autonomy, and social interactions [21], and allows learners to receive more specific comments [22]. Concerning peer feedback in the L2 writing classroom, some outstanding features have been underlined for it [23]. First, peer feedback is found useful by L2 learners. For example, Rollinson [24] disclosed that $80 \%$ of comments provided by peers were found valid, and around $7 \%$ were considered invalid. Second, peer feedback is perceived as a different kind from that of teachers. For instance, Caulk [25] uncovered that compared to teacher-led feedback, peer feedback was found more specific. Third, having the opportunity to read and comment critically on other peers' writings makes L2 learners more critical writers. Finally, peers are found more sympathetic compared to teachers who are more distant and judgmental [23].

In recent years, one of the most prominent peer-feedback approaches is OPF $[26,27]$. According to Mostert and Snowball [28], the quality of the peer-feedback process increases significantly in OPF. It provides ample opportunity for mingling support and learning. It is replete with ample hints and prompts allowing learners to receive more quality- relevant feedback from their peers [28, 29]. Additionally, as Mostert and Snowball [28] stressed, OPF increases the quality of assessment practices by reminding learners of the assessment quality criteria. One of the underlying reasons for the efficiency of OPF is that it enables learners to submit their work, review the previous materials, and revise their writings without any time and place limitations [18]. In online learning settings, learners can co-construct and reconstruct their knowledge by referring back to the shared posts and feedback [13]. The presence of materials and feedback allows L2 learners to reread and rethink them, leading to improved constructed knowledge [29, 30].

1.2. IELTS Writing. The large-scale ESL tests, such as the Test of English as a Foreign Language (TOFEL) and International English Language Testing System (IELTS), are widely used across the globe. These tests nowadays play a crucial role in many people's lives. They are used for making critical decisions, such as admissions to universities, migration, and job employments [31]. IELTS exam measures test-takers' performance to use English in communicative contexts. It entails four components, including listening, reading, writing, and speaking. The IELTS writing test is developed based on the recent developments in recent writing research and comprises communicative and contextualized tasks, addressing a specific audience, genre, and purpose [9]. According to Shaw [32], though there is no choice of topics, its developers claim that the given topics are continuously pretested to ensure their equality and comparability. IELTS exam has both general training and academic modules including two writing tasks per module. For writing task 1 , in the academic module, test takers need to write a report about a table or diagram in around 150 words in length. For task 2, they need to write a general report or short essay in response to a problem or argument in around 250 words in length. For task 1, in the general writing module, test takers should write a letter in response to a problem in 150 words in length. For task 2, in the general training module, test takers need to write an essay responding to a given problem or argument in 250 words in length. Both academic and general training modules take sixty minutes. It should be noted that the academic module is used to make decisions about university admission of students applying to international universities. However, the general training module is used to make decisions about undertaking work experience or training, meeting immigration requirements, and completing secondary education [9].

1.3. Online Peer Feedback and Writing. Facebook, Blog, Wiki, and, more recently, apps (e.g., WhatsApp) have provided the setting for OPF. Previous studies have supported the efficacy of OPF. For example, Tsai and Chuang [33] found that OPF was useful to improve learners' critical thinking and promote their motivation to revise their peers' writings. Furthermore, Xiao and Lucking [34] disclosed that peer feedback provided through a Wiki environment fostered the learners' writing performance and increased their 
satisfaction. Moreover, Shih [35] disclosed that the peer feedback offered through Blog was fruitful to evoke learners' interest and motivation and, consequently, to improve their writing performance. Likewise, Ciftci and Kocoglu [17] unveiled that the peer feedback offered through Blog had positive effects on learners' writing performance and their perceptions of technology use. More recently, in [13], the quality of writing performance was promoted due to the effects of the online argumentative peer-feedback script. Furthermore, Salavatizadeh and Tahriri [36] found that online automated feedback was as effective as teacher feedback to promote EFL learners' writing performance. Finally, Al Abri et al. [37] explored the effects of anonymous online peer feedback on EFL learners' essay writing performance in Omen. Their findings evidenced that the participants' writing performance significantly improved due to the positive effects of online peer feedback.

Though the above-alluded studies have confirmed the potentials of OPF to foster writing, its effects on the Iranian IELTS candidate's writing performance is under-researched. Considering the significance of writing skills for IELT candidates, it is essential to disclose the efficacy of OPF to promote writing skills. Furthermore, it is necessary to disclose the Iranian IELTS candidates' perceptions of the efficacy of OPF to promote their writing performance. To meet these objectives, the following research questions are put forward:

(1) Does online peer feedback lead to improving Iranian ILTS candidates' writing performance?

(2) Does online peer feedback lead to improving Iranian ILTS candidates' long-term retention writing performance?

(3) What are Iranian ILTS candidates' perceptions about the efficacy of online peer feedback to improve writing skills?

\section{Method}

2.1. Research Design. As, in the present study, the quantitative data were followed and supplemented by the qualitative data, the design was considered as an exploratory mixed-methods design. According to Riazi's [38] note, one of the outstanding features of the mixed-methods design is triangulation. Through triangulation, researchers get better and more accurate insights into the topic under research by approaching it from different perspectives, using different methods and techniques. Hence, to further our understanding of the effects of OPF on the improvement of Iranian IELTS candidates' writing skills, a mixed-methods approach was employed.

2.2. Setting and Participants. This study was conducted at Milad Language Institute, one of the established English institutes in IELTS preparation courses in Tehran, Iran, in the summer, 2021. A total of 98 IELTS candidates were selected using a convenient sampling method. The principal reason to select the participants was their availability to the researcher. To homogenize the participants, the Quick Oxford Placement Test (QOPT) was administered, and the participants whose scores fell 1 standard deviation below and above the mean were selected. The participants included both male $(n=17)$ and female $(n=20)$ and aged from 18 to 47 years. Afterward, they were randomly divided into two groups, namely, the experimental group $(n=18)$ and the control group $(n=19)$. They were learning English as a foreign language for 6 hours per week. The institute implemented communicative approaches, and the all language skills were covered in the curriculum. It should be noted that the researcher recruited a PhD in TEFL to run the classes for the two groups. To make sure that the instructor was familiar with the principles and procedures of OPF, the researcher held two sessions with him. During the treatment, the researcher monitored the two classes to ensure that they were run in line with the current study's objectives.

The researcher referred to the principal of Milad Language Institute, explained the current study's objectives, and asked if she could access the learners who were under the education for IELTS exam. Having received the principal's agreement, the researcher was led to the IELTS classes to explain the present study's objectives for the participants. She distributed written consent in Persian among the participants who were willing to participate in the study. The willing participant signed written consent and turned it back to the researcher. The researcher announced that participation in the study is voluntarily. Finally, she ensured that the participants' information would remain confidential and informed them about the final findings.

2.3. Instruments. The researcher used some instruments to collect the required data. The first instrument was the Oxford Quick Placement Test (OQPT) (Oxford University Press, 2001). This test is usually given to students entering an English institute to determine their proficiency levels with the purpose of assigning them to proper classes. The OQPT has been designed to meet some criteria: including current thinking on the nature of communicative language ability, entailing current thinking on how foreign languages are learned, consisting of the grammar and vocabulary included in Oxford University Press ELT course books, and comprising the types of errors that language learners typically make as they progress towards native-like ability to communicate in another language. It places students into six different proficiency levels (see Table 1). It entails $60 \mathrm{mul}$ tiple-choice test items (36 structure and 24 vocabulary), worth one mark for each item. The time allocated for each part is 30 and 45 minutes, respectively.

The other instrument was a smartphone. During the study, the researcher ensured that all the participants had a smartphone to connect to the web and install WhatsApp. WhatsApp is a cloud-based instant messaging service. It is available for free for both mobile (Android, iOS, Windows Phone, and Ubuntu Touch) and desktop systems (Windows, OS X, and Linux). Its users can send messages and exchange photos, videos, stickers, and files of any type. It also provides optional end-to-end encrypted messaging. The service also 
TABle 1: Conversion table of OQPT.

\begin{tabular}{lcc}
\hline Total score & Level & CEFR level \\
\hline $0-9$ & Beginner & A1 \\
$10-19$ & Elementary & A1+ to A2 \\
$20-29$ & Preintermediate & A2+ to B1 \\
$30-39$ & Intermediate & B1 \\
$40-49$ & Upper-intermediate & B2 \\
$50-60$ & Advanced & C1 \\
\hline
\end{tabular}

has group chats that can be private or public. WhatsApp groups are usually used for family and friendly gatherings and many other purposes such as business, and it is possible to add up to 200 people to them. Channel WhatsApp can also be used if the content is publicly displayed. Channels are capable of accepting an unlimited number of users and are a new tool that can help to send messages to millions of users. In the current research, due to the availability of all learners to the smartphone and WhatsApp, they were used for the intended purposes of this study.

The second instrument was the series of Mindset for IELTS books. The series is a modular IELTS preparation course in 4 levels: Foundation, 1, 2, and 3. It guides learners through all the skills and strategies they need to prepare for the IELTS test. It should be stressed that the parts covering the writing skills were used in the present study. The third instrument included three writing tests which were selected from the previous IELT sample test. However, to ensure that they are appropriate for the present study, two well-experienced IELTS trainers were asked to choose them. They were administered three times as pretest, immediate posttest, and delayed posttest. They were designed to assess a wide range of writing skills, including how well a test-taker writes a response appropriately, organizes ideas, and uses a range of vocabulary and grammatical structures accurately. The writing test took 60 minutes, and the learners were suggested to spend 20 minutes on task 1 . They were asked to write at least 150 words for task 1. In task 1, they were presented with a situation and asked to write a letter requesting information or explaining the situation. The participants' writings were rated through rubric writing. The rubric writing rated the participants' writings against the following criteria ([39], p. 163):

(1) Content. It needs to be relevant and sufficient. Relevant means the content is meaningful to the topic, and sufficient means that there is enough content (i.e., not too little and not too much).

(2) Organization. It means that content/ideas should be presented logically and grouped together or separated in meaningful ways.

(3) Language. It means that students need to make use of a range of grammatical and sentence structures accurately, to use a variety of vocabulary and expressions accurately, to use their punctuation correctly, and to use their spellings accurately.

(4) Task Requirement. It means that students need to follow the task requirements. For example, a task requirement for task 1 limits the students' writings to 150 words.
As every criterion scored 5 (poor $=1$, acceptable $=2$, average $=3$, good $=4$, and excellent $=5$ ), the whole score for a writing sample ranged from 5 to 20 . The researcher recruited two well-experienced IELTS examiners to administer the writing tests. It is worth noting that the researcher to examine if the writing tests enjoyed the need reliability and validity for the present study, she piloted them on a 20 IELTS-candidate sample. The reliability of the pretest was 0.84 , posttest was 0.92 , and delayed posttest was 0.79 . Regarding the validity, she used the experts' judgment strategy. That is, she gave the tests to three well-experienced IELTS trainers to investigate their validities. In general, the instructors confirmed that the instruments had a high level of face and content validity.

The last instrument was a focus group interview. At the end of the instruction, the researcher invited 5 participants of the experimental group to express their perceptions of the efficacy of OPF to improve their writing skills. For this purpose, the participants were invited to a class at Milad Language Institute. After a warm greeting, the researcher encouraged the participants to talk about their perceptions and experiences with OPF. Accompanied with the participants' words, the researcher asked questions and offered more prompts such that they can deal with all dimensions of the topic. The participants' words were recorded carefully to be analyzed later. It should be noted that the focus interview lasted two hours and was run in the participants' mother tongue, Persian, to let them express their views with greater ease.

2.4. Data Collection Procedures. To collect the required data, some steps were taken in order. At the first stage, the OQPT was run to homogenize the participants. The participants whose scores fell $1 \mathrm{SD}$ above and below the mean were selected and randomly assigned into groups, namely, the experimental group and control group. At the second stage, the pretest was administered to measure the participants' writing ability prior to the treatment. At the third stage, the treatments which lasted 15 sessions and held twice a week for the two groups were offered. For the experimental group, the participants were invited to join a WhatsApp group. After presenting the topic and activating the participants' background knowledge, the instructor provided them with the required key chunks and expressions. Then, the instructor encouraged the participants to write about the given topic. Upon encountering a problem, they could raise it into the WhatsApp group via text or voice. Afterward, the other peers tried to offer feedback so much so that the problem was completely rectified. For this purpose, at first, the peers offered indirect feedback. If it was not enough to rectify and correct the problem, they provided more explicit feedback. They continued offering feedback so much so that their peers could shape the required knowledge. Concerning the control group, the instructor provided direct feedback immediately. The other students were not allowed to help their peers handle the writing problems. At the fourth stage, the posttest was administered to gauge the participants' writing performance after the instruction. At the fifth stage, after one 
month, the delayed posttest was run to see if there was any statistical difference between the two groups' writing performance. At the last stage, the focus group interview was administered to disclose the participants' perceptions of the efficacy of OPF to improve their writing performance. It should be noted that the researcher recruited two experts in translation to translate the participants' words into English.

2.5. Data Analysis Procedures. As the collected data were quantitative and qualitative, the data analysis procedures were done in two phases. At the first phase, the quantitative data were analyzed using SPSS version 22. Along with measures of central tendency and those of variability for all the given measures above, a test of ANCOVA was run to identify the differences between the two groups in terms of their gain scores across the three test administrations. At the second phase, the qualitative data were analyzed through a content analysis approach. Content analysis is considered as a detailed and systematic description of the manifest content of communication to identify patterns or themes [40]. The researcher followed three steps to do the content analysis, including open coding, axial coding, and selective coding [41]. In the open coding step, the transcripts were read so much so that the researchers could make enough sense of them. In the axial coding step, the major themes were elicited and verified. The selective coding was focused on putting the participants' perceptions under the inductively generated themes. It is worth noting that the researcher recruited two coding analysts to analyze the data, and the reliability of their inter-rater was $\alpha=0.95$. A member checking strategy was also used to assess the accuracy and credibility of the participants' responses. A copy of the final findings was given to three interviewees to check if they represented their intended meanings. In general, they affirmed that the findings represented their intended meanings accurately.

\section{Results}

3.1. Quantitative Results. The first research question investigated whether there was a significant difference between the immediate posttest scores as a result of two types of instruction (i.e., OPF and non-peer-feedback), while the effect of the pretest (covariate) was controlled. To this purpose, a one-way ANCOVA was run. Prior to proceeding with the main analysis, the assumptions associated with this statistical procedure were examined. To check the assumption of linearity, the distribution of scores for each of the groups was checked on the scatterplot matrix, and no curvilinear relationship was observed. Besides, concerning the normality assumption, the results of the Kolmogorov-Smirnov test showed that the Sig. values $(0.30)$ for the scores on the posttest were larger than the critical value (0.05). Hence, it approved that the data are normally distributed. Furthermore, Levene's test of the equality of the variances indicated that the variability of scores for each of the groups was similar because the Sig. level (0.09) was larger than the alpha level (0.05). Thus, this assumption was also met. In addition, the homogeneity assumption of regression slopes was assessed statistically via the Sig. value of interaction (i.e., instruction* pretest) (Sig. $=0.48, P>0.05)$. This assumption was also observed.

Having assured that the basic assumptions were met, the descriptive statistics on the immediate posttest scores between the groups are summarized in Table 2.

As shown in Table 2, the results indicate that there was a difference between the means of the immediate posttest scores between the groups; thus, to see whether the difference was significant and how much of the difference was due to the effect of the independent variable (i.e., instruction type), the inferential statistics were taken into consideration.

As depicted in Table 3, there was a significant difference between the posttest scores due to the effect of treatment type $(F(1,26)=51.7, P<0.001$, partial eta squared $=0.68)$. It implies that about 68 percent of the differences can be ascribed to the role of intervention type (i.e., independent variable). However, the effect of difference in pretest scores on the posttest performance was also significant $(F(1,26)=$ $6.00, P<0.00$, partial eta squared $=0.15)$. It means that only 15 percent of the difference can be explained by the differences in pretest scores. Next, the table of estimated marginal means was consulted to assess the adjusting means on the dependent variable (i.e., the instruction type) for each of the groups in order to remove the effect of the covariate on the immediate posttest scores. The results are presented in Table 4.

As reported in Table 5, after adjusting for pretest scores, a significant difference between OPF and non-OPF groups in terms of gains in writing performance was revealed $(F(1$, 26) $=48.3, P=0.00$, partial eta squared $=0.69$ ).

By consulting the significance values, it can clearly be observed that there was a statistically significant difference between OPF and non-OPF groups in terms of their performance on the posttest. The findings are presented in Table 6.

The second research question intended to explore whether there was a significant difference between the experimental and control groups' long-term retention of writing performance, whereas the effect of the pretest (covariate) was controlled. To this aim, a one-way ANCOVA was run. Like the previous question, before running the main ANCOVA, the assumptions were investigated. Initially, for the assumption of linearity, the distribution of scores for each of the groups was checked on the scatterplot, and no curvilinear relationship was observed. Then, to check the normality assumption, Kolmogorov-Smirnov test was used based on which the Sig. levels $(0.26)$ for the scores on the delayed posttest were greater than the critical value (0.05). Therefore, the assumption of normality was confirmed. In addition, the results of Levene's test $(F=3.008, P>0.05)$ also approved the assumption of equal variances. To answer the second question, therefore, like the previous question, a parametric data analysis technique, one-way ANCOVA, was employed. Furthermore, the homogeneity assumption of regression slopes was assessed statistically through the Sig. value of interaction (i.e., instruction ${ }^{*}$ pretest) (Sig. $=0.09$, $P>$.05). This assumption was also met. 
TABLe 2: Descriptive statistic for comparing the online peer feedback and non-peer-feedback.

\begin{tabular}{lccc}
\hline & Dependent variable: immediate posttest & & \\
Instruction & $\mathrm{M}$ & SD & \\
\hline Online peer feedback & 13.38 & 3.031 & 18 \\
Non-peer-feedback & 8.22 & 2.342 & 19 \\
Total & 10.8 & 2.686 & 27 \\
\hline
\end{tabular}

TABLE 3: Inferential statistic for comparing the online peer feedback and non-peer-feedback.

\begin{tabular}{lcccccc}
\hline \multicolumn{5}{c}{$\begin{array}{c}\text { Tests of between-subject effects } \\
\text { Dependent variable: immediate posttest }\end{array}$} \\
Source & Type III sum of squares & $\mathrm{df}$ & Mean square & $F$ & Sig. & Partial eta squared \\
\hline Corrected model & $442.329^{\mathrm{a}}$ & 2 & 221.164 & 40.023 & 0.000 & 0.680 \\
Intercept & 188.332 & 1 & 188.332 & 54.876 & 0.000 & 0.654 \\
Pretest & 31.035 & 1 & 31.035 & 6.008 & 0.033 & 0.151 \\
Instruction & 169.881 & 1 & 169.881 & 51.762 & 0.000 & 0.682 \\
Error & 77.337 & 24 & 3.222 & & & \\
Total & 21986.000 & 27 & & & \\
Corrected total & 788.400 & 26 & & & \\
\hline
\end{tabular}

${ }^{\mathrm{a}} R$ squared $=0.680$ (adjusted $R$ squared $=0.653$ ).

TABle 4: Estimated marginal means.

Dependent variable: immediate posttest

\begin{tabular}{lcccc} 
Instruction & Mean & Std. error & \multicolumn{2}{c}{$\begin{array}{c}95 \% \text { confidence interval } \\
\text { Upper bound }\end{array}$} \\
\hline Online peer feedback & $13.806^{\mathrm{a}}$ & 0.512 & 21.615 & 24.243 \\
Non-peer-feedback & $8.011^{\mathrm{a}}$ & 0.512 & 11.018 & 14.002 \\
\hline
\end{tabular}

${ }^{\mathrm{a} C o v a r i a t e s}$ appearing in the model are evaluated at the following values: pretest $=4.55$.

TABLE 5: Univariate tests.

\begin{tabular}{lcccccc}
\hline & Sum of squares & $\mathrm{df}$ & Mean square & $F$ & Sig. & Partial eta squared \\
\hline Contrast & 187.423 & 1 & 187.423 & 48.301 & 0.000 & 0.689 \\
Error & 76.762 & 24 & 4.001 & & & \\
\hline
\end{tabular}

$F$ tests the effect of instruction. This test is based on the linearly independent pairwise comparisons among the estimated marginal means.

TABLE 6: Pairwise comparisons of online peer feedback and non-peer-feedback groups on the posttest.

\begin{tabular}{|c|c|c|c|c|c|c|}
\hline & & Pairwise compariso & & & & \\
\hline & & pendent variable: immed & e posttest & & & \\
\hline & $(J)$ instruction & Mean difference $(I-J)$ & Std. error & Sig. ${ }^{a}$ & $\begin{array}{r}95 \% \text { confide } \\
\text { dif }\end{array}$ & $\begin{array}{l}\text { e interval for } \\
\text { ence }\end{array}$ \\
\hline & & & & & Lower bound & Upper bound \\
\hline Online peer feedback & Non-peer-feedback & $5.795^{*}$ & 0.566 & 0.000 & 3.016 & 5.717 \\
\hline Non-peer-feedback & Online peer feedback & $-5.795^{*}$ & 0.566 & 0.000 & -5.417 & -3.016 \\
\hline
\end{tabular}

Based on estimated marginal means, *the mean difference is significant at the 0.05 level. ${ }^{a}$ Adjustment for multiple comparisons: least significant difference (equivalent to no adjustments).

The descriptive statistics in Table 7 revealed that there was a difference of mean between the delayed posttest scores between the two groups. Hence, to see whether the difference was significant and how much of the difference was due to the impact of the independent variable and instruction type, the inferential statistics were run (Table 8).

As displayed in Table 8, there was a significant difference between the delayed posttest scores of the groups because of 
TABle 7: Descriptive statistic for comparing the online peer feedback and non-peer-feedback on delayed posttest.

\begin{tabular}{lccc}
\hline & Descriptive statistics & & \\
& Dependent variable: delayed posttest & & \\
Instruction & $\mathrm{M}$ & 2.811 & $\mathrm{ND}$ \\
\hline Online peer feedback & 14.611 & 2.010 & 18 \\
Non-peer-feedback & 6.088 & 4.821 & 19 \\
Total & 10.349 & 27 \\
\hline
\end{tabular}

TABLE 8: Inferential statistic for comparing the post- and delayed posttest scores of online peer feedback and non-peer-feedback.

\begin{tabular}{|c|c|c|c|c|c|c|}
\hline \multicolumn{7}{|c|}{ Tests of between-subject effects } \\
\hline \multicolumn{7}{|c|}{ Dependent variable: delayed posttest } \\
\hline Source & Type III sum of squares & df & Mean square & $F$ & Sig. & Partial eta squared \\
\hline Corrected model & $387.234^{\mathrm{a}}$ & 2 & 197.617 & 58.412 & 0.000 & 0.624 \\
\hline Intercept & 134.567 & 1 & 134.567 & 61.045 & 0.000 & 0.714 \\
\hline Pretest & 36.587 & 1 & 36.587 & 11.901 & 0.002 & 0.223 \\
\hline Instruction & 234.210 & 1 & 234.210 & 76.103 & 0.000 & 0.646 \\
\hline Error & 81.666 & 24 & 3.402 & & & \\
\hline Total & 2667.000 & 27 & & & & \\
\hline Corrected total & 406.500 & 26 & & & & \\
\hline
\end{tabular}

${ }^{\mathrm{a}} R$ squared $=0.770$ (adjusted $R$ squared $=0.742$ ).

the effect of treatment type $(F(1,26)=76.1, P<.001$, partial eta squared $=0.64)$. In other words, about 64 percent of the differences can be attributed to the role of intervention type, OPF, and non-OPF. However, the effect of difference in posttest scores on the delayed posttest performance was also significant $(F \quad(1,26)=11.9, \quad P<.001$, partial eta squared $=0.22$ ). That is, only 22 percent of the difference can be explained by the differences in posttest scores. To remove the impact of the covariate on the immediate posttest scores, estimated marginal means were taken into consideration. The findings are presented in Table 9.

After adjusting for pretest scores, a significant difference between OPF and non-OPF groups in terms of gains in writing performance was revealed $(F(1,29)=77.2, P=0.00$, partial eta squared $=0.60)$. The results are shown in Table 10 .

By consulting the significance values, it can be observed that there was a statistically significant difference between OPF and non-OPF groups in terms of their performance on the delayed posttest, as presented in Table 11.

3.2. Qualitative Results. The third research question explored the participants' perceptions of the efficacy of OPF to improve their writing performance. The findings disclosed that the participants enjoyed positive attitudes toward the use of OPF to improve their writing performance. To support this, one of the participants remarked:

"Using apps like WhatsApp and joining online platforms have many noticeable advantages to learning English. For example, I've currently joined a WhatsApp group consisting of many IELTS candidates. Every day, they share many interesting contents which I use to improve my writing skills.”
Corroborating with the previous statement, another participant confirmed that online feedback provided through online sharing instruments was really fruitful as the feedback was multimedia. In this regard, she quoted:

"My reason to advocate the efficacy of online peer feedback is that it is a valuable resource. Take an example, online sharing resources such as WhatsApp are multimedia. I mean that they can provide the visual and audio input for users. To improve my writing, I could see the written form as well as listen to my peers' feedback."

Consistent with the previous statements, one of the participants underlined that learning through online sharing is highly flexible. In this regard, she stated:

"The big advantage of learning through WhatsApp was that it was not limited by the time and place. I mean that when you are in your bedroom, when you are on bus, when you are walking in the park, you can use them as an invaluable source to improve your writing skills. For instance, when I go home from work, I can benefit from the content shared within the group by other peers."

In line with the previous statements, another participant emphasized:

"We used WhatsApp to schedule meetings, to post a link to information to discuss relevancy, to communicate whenever we had problems or questions, and to give feedback. We were much more comfortable using WhatsApp to communicate. We got quick notifications from WhatsApp when someone posted a change in the meeting location or the meeting time." 
TABLE 9: Estimated marginal means.

\begin{tabular}{lcccc}
\hline & & $\begin{array}{c}\text { Estimated marginal means } \\
\text { Dependent variable: delayed posttest }\end{array}$ & \\
Instruction & Mean & Std. error & Lower bound confidence interval & Upper bound \\
\hline Online peer feedback & $14.201^{\mathrm{a}}$ & 0.488 & 13.312 & 16.234 \\
Non-peer-feedback & $5.713^{\mathrm{a}}$ & 0.488 & 4.876 & 6.801 \\
\hline
\end{tabular}

${ }^{\mathrm{a} C o v a r i a t e s}$ appearing in the model are evaluated at the following values: pretest $=2.88$.

TABLE 10: Univariate tests.

\begin{tabular}{lccccr}
\hline & \multicolumn{4}{c}{ Dependent variable: delayed posttest } \\
Sum of squares & $\mathrm{df}$ & Mean square & $F$ & Sig. & Partial eta squared \\
\hline Contrast & 245.734 & 1 & 245.734 & 77.212 & 0.000 \\
Error & 77.813 & 24 & 3.242 & & 0.601 \\
\hline
\end{tabular}

$F$ tests the effect of instruction. This test is based on the linearly independent pairwise comparisons among the estimated marginal means.

TABLE 11: Pairwise comparisons.

Dependent variable: delayed posttest

\begin{tabular}{|c|c|c|c|c|c|c|}
\hline \multirow[t]{2}{*}{ (I) instruction } & \multirow[t]{2}{*}{$(J)$ instruction } & \multirow{2}{*}{ Mean difference $(I-J)$} & \multirow[t]{2}{*}{ Std. error } & \multirow[t]{2}{*}{ Sig. ${ }^{\text {a }}$} & \multicolumn{2}{|c|}{$\begin{array}{l}\text { 95\% confidence interval for } \\
\text { difference }\end{array}$} \\
\hline & & & & & Lower bound & Upper bound \\
\hline Online peer feedback & Non-peer-feedback & $8.523^{*}$ & 0.582 & 0.000 & 7.341 & 9.009 \\
\hline Non-peer-feedback & Online peer feedback & $-8.523^{*}$ & 0.582 & 0.000 & -9.009 & -7.341 \\
\hline
\end{tabular}

Based on estimated marginal means, ${ }^{*}$ the mean difference is significant at the 0.05 level. ${ }^{a}$ Adjustment for multiple comparisons: least significant difference (equivalent to no adjustments).

Congruent with the previous comments, one of the participants pinpointed that the materials shared and the feedback provided on the WhatsApp group were available for a long time. The following excerpt shows his comment:

"I think that the biggest advantage of online peer feedback was that it remained there for a long time. I mean that when I have a question or problem with respect to my writing, I could post my question. Then, the other students could see my question and provide the required feedback. That feedback was present there so that I could benefit from it."

Finally, the participants pinpointed that online learning was interesting to them. In this respect, one of the participants commented:

"Attending real English courses was fully boring for me. However, participating in these virtual classes truly raised my interest. In fact, this new world has made me interested in learning English."

In brief, from the quotations presented above, it can be inferred that the Iranian IEFL learners have, to a large extent, positive attitudes toward the use of the social networking tools in their academic life. As can be seen from the words of the participants, it can be clearly said that social networking such as WhatsApp could pave the way for the learners to cultivate their writing performance. Indeed, the words of the interviewees asserted that social networking should be regarded as asserted that should be used in the modern second-language acquisition.

\section{Discussion}

The first research question investigated if OPF leads to improving Iranian IELTS learners' writing performance. The findings evidenced that the experimental group receiving OPF outperformed the control group. That is, in line with the results, it can be argued that the OPF paved the way for the experimental group to improve their writings from the pretest to the posttest. In this regard, it can be argued that, due to the instruction offered based on the principles and procedures, peer feedback led the participants to rectify and correct their writing problems and construct the required knowledge and skills.

The second research question examined if OPF leads to improving Iranian ILTS candidates' long-term retention writing. The findings documented that the experimental group's writing performance significantly improved on the delayed posttest compared with the control group. The results indicated that the OPF enabled the experimental group to have a better performance after one month. Aligning with the study's findings, it can be argued that this significant improvement may be due to the constructive feedback provided by the peers through WhatsApp. Since 
the peer feedback might have assisted the learners to internalize the required skills to write well, they were capable of retrieving them after a long time.

The third research question explored the Iranian IELTS candidates' perceptions of the efficacy of OPF to improve writing abilities. The results disclosed that the participants had positive attitudes toward OPF. The participants pinpointed that using online sharing network, such as WhatsApp, was highly promising to hone their writing performance. They all agreed that the online class let them access invaluable resources to diagnose their writing problems and remove them effectively. Aligning with the findings, it can be argued that the instruction provided through WhatsApp was found a continuous process wherein learning and assessment never end. The participants' positive attitudes may lie in this fact that the online sharing network might have opened up this opportunity to learn and practice writing the walls of classrooms. Additionally, the study's findings can be discussed from this view that the participants might have found the use of multimedia (text, audio, and video) more effective than the traditional medium offered through textbooks.

The study's results are consistent with the previous studies [13, 42-44], indicating that learning English as a second language via social networking applications was found more promising for L2 learners. However, the study's findings are in contrast with those of Dehghan et al. [45], revealing that the use of WhatsApp to learn was not fruitful. Additionally, the qualitative study's findings are consistent with previous studies [36, 46-49], reporting positive perceptions of EFL learners toward the use of the social network to improve writing skills. Additionally, the findings of the study are consistent with those of López-Pellisa et al. [50], reporting that when peer feedback is used in collaborative writing, the participants responded more reflectively and constructively. Finally, the study's findings lend credence to those of Al Abri et al. [37], indicating that the participants' writing performance significantly improved due to the positive effects of online peer feedback.

One possible explanation of the findings may lie in collaborative e-learning. Collaborative e-learning for the study's findings might be explained from a constructivist view of learning associated with Vygotsky's [16] Zone of Proximal Development (ZPD). From this perspective, it can be argued that the learners' understanding and cognitive development might have been shaped through the social interactions with other peers. In other words, collaborative e-learning might have acted as active construction of knowledge where the learners might have shared their ideas and information through the group communication in the social networking. These findings lend support to the words of Haythornthwaite [51], claiming that "collaboration entails working together toward a common goal" (p. 7). During the instruction, the participants might work together to move toward the same goal by handling the requirements of a wellorganized writing. In the online classroom, the collaboration acted as a social process in which the IELTS candidates might have worked together to handle a writing task in which no single hand could reach the intended achievement. Furthermore, the study's findings might be attributed to other benefits of collaborative e-learning. Along with Haythornthwaite [51], it may be argued that collaborative e-learning might have assisted the learners to do and achieve more together than they could alone. The community was established where the learners were fully engaged in collaborative activities constructing meaningful and worthwhile knowledge of the target writing skills.

Another line of discussion can be ascribed to the basic tenets of peer learning. Peer learning is characterized by specific role-taking as a tutor or tutee, with a high focus on curriculum content and usually also on clear procedures for interaction, in which participants receive generic and/or specific training [52]. In line with peer learning, it might be argued that peers in the peer-feedback group set the scene for the acquisition of the target writing rules through active helping and supporting other students in which they all acted as matched companions. It might have involved the students from similar social groupings helping each other to learn [53]. This cooperative climate where the feedback was provided by the students might have helped them construct the required knowledge to handle the writing tasks.

One more possible explanation of the study's results may be attributed to online discussion forums (ODFs) [54]. In line with ODFs, it might be argued that WhatsApp might have provided an effective setting to support collaboration, reflection, and professional development, as well as to overcome the barriers of time and place. It could provide the learners with some extra time to reflect on the previous postings to the discussion thread [55]. As Balaji and Chakrabarti [56] noted, this e-learning platform might have allowed the students to post messages to the discussion threads, interacted and received feedback from other students, and fostered a deeper understanding toward the requirements of the writing. Furthermore, ODF can also be seen as a virtual learning environment where the students might have had the opportunity to learn from each other, as well as from course materials [57].

Furthermore, the study's findings may be ascribed to cognitive psychology. In line with Hulstijn and Laufer [58], it can be argued that the more the learners paid attention to the basic features of the writing requirements, the more likely it is that they might have been retained by the learners. In other words, the peer feedback offered to the participants might have helped them give much attention to the intended structures such that they might have had a better opportunity to be stored in the learners' memories. This argument receives support from "Involvement Load Hypothesis." [59] It is argued that the retention of key structures to write well was, generally, conditional upon the degree of involvement in processing these structures. The peer feedback provided on the social networking might have helped the students to engage more in the learning processes of the writing aspects by increasing the involvement load. 


\section{Conclusion}

As noted above, the present study purported to investigate the effects of OPF on the improvement of Iranian IELTS candidates' writing abilities. The findings evidenced that the experimental group outweighed the control group on both posttest and delayed posttest. Additionally, the results documented that the participants had positive attitudes toward the efficiency of OPF in improving writing skills. All in all, according to the findings, it can be concluded that IELTS candidates may construct their own meaning and understanding of what they require to learn by using social networking facilities. By using social networking apps such as WhatsApp, the participants could be involved in the search, collection, analysis, evaluation, integration, and use of shared information to overcome their writing problems. In this way, they could participate mentally, emotionally, and socially in the constructive virtual dialogues to coconstruct the required knowledge and skills of writing.

In light of the study's findings, some implications are presented. First, social networking applications, such as WhatsApp, can be considered as a useful tool not only to transmit information, awaken people toward politics, and inform them about new technologies, but it can also be regarded as a useful educational tool to facilitate learning. As such, it is recommended to embrace social networking apps with open arms by the educational administrators, in general, and English practitioners, in particular. Second, social networking apps are able to provide L2 learners with excellent opportunities to learn without requiring an instructor to convey the accessible information. Consequently, they can make a necessary shift in teaching patterns from the highly teacher-centered to learner-centered paradigm. Third, the material developers can benefit from social networking apps such that the new educational materials should include and benefit from them. Additionally, material developers should design the materials which are suitable for online learning. Fourth, IELTS instructors can use peer feedback via social networking apps in their profession. They can use OPF as a fruitful approach to improve their writing skills without the limitation of time and location. Fifth, IELTS learners should not take advantage of the social networking apps by joining groups and channels. There, they can find invaluable resources to consolidate their learning. Last but not least, the language institute owners need to equip their institutes with modern social networking technologies such that learners can benefit from the online courses.

In light of the limitations imposed on the present study, some suggestions for further research are presented. First, as the present study focused on writing skills, future studies can explore the effects of OPF on improving other language skills and components. Second, as the sample of the present study was restricted to one language institute, more studies are needed to include larger samples of IELTS candidates to increase the generalizability of the study's findings. Third, since the current study was conducted with IELTS candidates, future studies can entail learners from high schools and higher education centers. Last but not least, longitudinal studies are required to explore how OPF can lead to improving L2 learning with the cross of time.

\section{Data Availability}

The data used to support the findings of this study are available upon request to the author.

\section{Conflicts of Interest}

The author declares that there are no conflicts of interest.

\section{References}

[1] B. Naghdipour, "English writing instruction in Iran: implications for second language writing curriculum and pedagogy," Journal of Second Language Writing, vol. 32, pp. 81-87, 2016.

[2] M. Hyland, Writing Text Types: A Practical Journal, RIC Publications, Balcatta, Australia, 2009.

[3] N. Browker, Academic Writing: A Guide to Tertiary Level Writing, Massey University, Palmerston North, New Zealand, 2007.

[4] K. Hyland, English for Academic Purposes: An Advanced Resource Book, Routledge, London, UK, 2006.

[5] J. Richards, Language Teaching Matrix, Cambridge University Press, Cambridge, UK, 1990.

[6] T. Tajmirriahi and E. Rezvani, "Learner autonomy in L2 writing: the role of academic self-concept and academic achievement," Educational Research International, vol. 2021, Article ID 6074039, 10 pages, 2021.

[7] H. D. Brown, Teaching by Principles, Pearson Education, London, UK, 5th edition, 2015.

[8] B. Azabdaftari and M. A. Mozaheb, "Comparing vocabulary learning of EFL learners by using two different strategies: mobile learning vs. flashcards," The Eurocall Review, vol. 20, no. 2, pp. 47-59, 2012.

[9] H. H. Uysal, "A critical review of the IELTS writing test," ELT Journal, vol. 64, no. 3, pp. 314-320, 2010.

[10] T. Moore and J. Morton, "Dimensions of difference: a comparison of university writing and IELTS writing," Journal of English for Academic Purposes, vol. 4, no. 1, pp. 43-66, 2005.

[11] L. A. Stern and A. Solomon, "Effective faculty feedback: the road less traveled," Assessing Writing, vol. 11, no. 1, pp. 22-41, 2006.

[12] M. M. Nelson and C. D. Schunn, "The nature of feedback: how different types of peer feedback affect writing performance," Instructional Science, vol. 37, no. 4, pp. 375-401, 2008.

[13] O. Noroozi, H. Biemans, and M. Mulder, "Relations between scripted online peer feedback processes and quality of written argumentative essay," The Internet and Higher Education, vol. 31, pp. 20-31, 2016.

[14] V. J. Shute, "Focus on formative feedback," Review of Educational Research, vol. 78, no. 1, pp. 153-189, 2008.

[15] J. Liu and J. Hansen, Peer Response in Second Language Writing Classrooms, Ann Arbor, MI, USA, 2002.

[16] L. S. Vygotsky, Mind and Society: The Development of Higher Mental Processes, Harvard University Press, Cambridge, MA, USA, 1978.

[17] H. Ciftci and Z. Kocoglu, "Effects of peer E-feedback on Turkish EFL students' writing performance," Journal of Educational Computing Research, vol. 46, no. 1, pp. 61-84, 2012.

[18] E. Z. Eric Zhi-Feng Liu, S. S. J. Lin, C. H. Chi-Huang Chiu, and S. M. Shyan-Ming Yuan, "Web-based peer review: the 
learner as both adapter and reviewer," IEEE Transactions on Education, vol. 44, no. 3, pp. 246-251, 2001.

[19] P. Hyland, "Learning from feedback on assessment," in The Practice of University History Teaching, A. Booth and P. Hyland, Eds., Manchester University Press, Manchester, UK, 2000.

[20] F. Yarrow and K. J. Topping, "Collaborative writing: the effects of metacognitive prompting and structured peer interaction," British Journal of Educational Psychology, vol. 71, no. 2, pp. 261-282, 2001.

[21] M. Yang, R. Badger, and Z. Yu, "A comparative study of peer and teacher feedback in a Chinese EFL writing class," Journal of Second Language Writing, vol. 15, no. 3, pp. 179-200, 2006.

[22] K. Lundstorm and W. Baker, "To give is better than to receive: the benefits of pee review to the reviewer's own writing," Journal of Second Language Writing, vol. 18, no. 1, pp. 30-43, 2009.

[23] P. Rollinson, "Using peer feedback in the ESL writing class," ELT Journal, vol. 59, no. 1, pp. 23-30, 2005.

[24] P. Rollinson, Peer Response and Revision in an ESL Writing Group: A Case Study, Ph. D thesis, Universidad Autónoma de Madrid, Madrid, Spain, 1998.

[25] N. Caulk, "Comparing teacher and student responses to written work," TESOL Quarterly, vol. 28, no. 1, pp. 181-188, 1994.

[26] Y. C. Chen and C. C. Tsai, "An educational research course facilitated by online peer assessment," Innovations in Education and Teaching International, vol. 46, no. 1, pp. 105-117, 2009.

[27] T. N. Pham, M. Lin, V. Q. Trinh, and L. T. P. Bui, "Electronic peer feedback, EFL academic writing and reflective thinking: evidence from a Confucian context," Sage Open, vol. 10, no. 1, 2020.

[28] M. Mostert and J. D. Snowball, "Where angels fear to tread: online peer-assessment in a large first-year class," Assessment \& Evaluation in Higher Education, vol. 38, no. 6, pp. 674-686, 2013.

[29] O. Noroozi, H. J. A. Biemans, M. C. Busstra, M. Mulder, and M. Chizari, "Differences in learning processes between successful and less successful students in computer-supported collaborative learning in the field of human nutrition and health," Computers in Human Behavior, vol. 27, no. 1, pp. 309-318, 2011.

[30] F. P. C. M. De Jong, A. E. Veldhuis-Diermanse, and G. Lutgens, "Computer-supported learning in university and vocational education," in CSCL 2: Carrying Forward the Conversation, T. Koschman, R. Hall, and N. Miyake, Eds., pp. 111-128, Erlbaum, Mahwah, NJ, USA, 2002.

[31] T. Clark and G. Yu, "Beyond the IELTS test: Chinese and Japanese postgraduate UK experiences," International Journal of Bilingual Education and Bilingualism, vol. 24, pp. 1-19, 2020.

[32] S. D. Shaw, "IELTS writing: revising assessment criteria and scales (phase 3)," Research Notes, vol. 16, pp. 3-7, 2004.

[33] Y.-C. Tsai and M.-T. Chuang, "Fostering revision of argumentative writing through structured peer assessment," Perceptual and Motor Skills, vol. 116, no. 1, pp. 210-221, 2013.

[34] Y. Xiao and R. Lucking, "The impact of two types of peer assessment on students' performance and satisfaction within a Wiki environment," The Internet and Higher Education, vol. 11, no. 3-4, pp. 186-193, 2008.

[35] R. C. Shih, "Can Web 2.0 technology assist college students in learning English writing? Integrating Facebook and peer assessment with blended learning," Australasian Journal of Educational Technology, vol. 27, no. 5, pp. 829-845, 2011.
[36] M. Salavatizadeh and A. Tahriri, "The effect of blended online automated feedback and teacher feedback on EFL learners' essay writing ability and perception," Teaching English as a Second Language (Formerly Journal of Teaching Language Skills), vol. 39, no. 32, pp. 181-225, 2020.

[37] A. Al Abri, S. Al Baimani, and S. Bahlani, "The role of webbased peer feedback in advancing EFL essay writing," Computer-Assisted Language Learning Electronic Journal (CALLEJ), vol. 22, no. 1, pp. 374-390, 2021.

[38] A. M. Riazi, The Routledge Encyclopedia of Research Methods in Applied Linguistics, Routledge, London, UK, 2016.

[39] D. Nunan, Task-based Language Teaching, Ernst Klett Sprachen, Chicago, IL, USA, 2004.

[40] J. W. Cresswell and Ch. N. Poth, Qualitative Inquiry \& Research Design: Choosing Among Five Approaches, SAGE Publications, Thousand Oaks, CA, USA, 4th edition, 2018.

[41] J. W. Creswell and J. D. Creswell, Research Design: Qualitative, Quantitative, and Mixed Methods Approaches, SAGE Publications, Thousand Oaks, CA, USA, 2017.

[42] W. Bouhami, Investigating the Impact of Social Media on Improving EFL Students' Vocabulary, M S. thesis, Mohammed Kheider University of Biskra, People's Democratic Republic of Algeria, Biskra, Algeria, 2016.

[43] A. Khan, O. Egbue, B. Palkie, and J. Madden, "Active learning: engaging students to maximize learning in an online course," Electronic Journal of E-Learning, vol. 15, no. 2, pp. 107-115, 2017.

[44] F. Khansarian-Dehkordi and A. Ameri-Golestan, "Effects of social networking on Iranian EFL learners' vocabulary acquisition," Research in English Language Pedagogy, vol. 5, no. 2, pp. 97-111, 2017.

[45] F. Dehghan, R. Rezvani, and S. Fazeli, "Social networks and their effectiveness in learning foreign language vocabulary: a comparative study using WhatsApp," CALL-EJ, vol. 18, no. 2, pp. 1-13, 2017.

[46] G. Cheng, "The impact of online automated feedback on students' reflective journal writing in an EFL course," The Internet and Higher Education, vol. 34, pp. 18-27, 2017.

[47] Y.-H. Lai, "Which do students prefer to evaluate their essays: peers or computer program," British Journal of Educational Technology, vol. 41, no. 3, pp. 432-454, 2010.

[48] J. Li, S. Link, and V. Hegelheimer, "Rethinking the role of automated writing evaluation (AWE) feedback in ESL writing instruction," Journal of Second Language Writing, vol. 27, pp. 1-18, 2015.

[49] B. Zheng, M. Warschauer, and G. Farkas, "Digital writing and diversity: the effects of school laptop programs on literacy processes and outcomes," Journal of Educational Computing Research, vol. 48, no. 3, pp. 267-299, 2013.

[50] T. López-Pellisa, N. Rotger, and F. Rodríguez-Gallego, "Collaborative writing at work: peer feedback in a blended learning environment," Education and Information Technologies, vol. 26, no. 1, pp. 1293-1310, 2021.

[51] C. Haythornthwaite, "Facilitating collaboration in online learning," Journal of Asynchronous Learning Networks, vol. 10, no. 1, pp. 7-24, 2006.

[52] K. J. Topping, "Trends in peer learning," Educational Psychology, vol. 25, no. 6, pp. 631-645, 2005.

[53] D. Boud and R. Cohen, Peer Learning in Higher Education: Learning from and with Each Other, Routledge, London, UK, 2014.

[54] L. F. Pendry and J. Salvatore, "Individual and social benefits of online discussion forums," Computers in Human Behavior, vol. 50, pp. 211-220, 2015. 
[55] T. Anderson and H. Kanuka, "On-line forums: new platforms for professional development and group collaboration," Journal of Computer-Mediated Communication, vol. 3, no. 3, Article ID JCMC332, 1997.

[56] M. S. Balaji and D. Chakrabarti, "Student interactions in online discussion forum: empirical research from "media richness theory" perspective," The Journal of Interactive Online Learning, vol. 9, no. 1, 2010.

[57] M. J. W. Thomas, "Learning within incoherent structures: the space of online discussion forums," Journal of Computer Assisted Learning, vol. 18, no. 3, pp. 351-366, 2002.

[58] B. Laufer and J. Hulstijn, "Incidental vocabulary acquisition in a second language: the construct of task-induced involvement," Applied Linguistics, vol. 22, no. 1, pp. 1-26, 2001.

[59] A. Yanagisawa and S. Webb, "To what extent does the involvement load Hypothesis predict incidental L2 vocabulary learning? A meta-analysis," Language Learning, vol. 71, no. 2, pp. 487-536, 2021. 